\title{
RELATIONSHIP BETWEEN MUSCLE STRENGTH OF DOMINANT AND NON-DOMINANT ANKLE AND DYNAMIC BALANCE IN FOOTBALL PLAYERS
}

\author{
Mert Isbilir ${ }^{1}$, Anna Zuša ${ }^{2}$, Onur Oral ${ }^{3}$, Refik Cabuk ${ }^{3}$ \\ Aristotle University', Thessaloniki, Greece \\ Latvian Academy of Sport Education', Riga, Latvia \\ Ege University ${ }^{3}$ Izmir, Turkey
}

\begin{abstract}
Background. Developing lower extremity muscles in a proportional shape plays an important role of balanced body movement. It is believed that special development of muscles which provide multidirectional movements of ankle will contribute to the increase of balance ability, and this may significantly support the improvement of technical skill performance in football. The aim of the research was to examine the ability to keep dynamic balance and ankle joint muscle strength in football players, and to prove the relation between the ankle joint muscle strength level and the dynamic balance ability of each foot.

Methods. The participants were amateur footballers $(n=17$, football experience $10 \pm 1$.4years, weekly training $12 \pm 1.3 \mathrm{~h}$ ). "WFQ-R poll" questionnaire was used to determine the participants' dominant and non-dominant limb, the dynamic balance was assessed using "Tecnobody Pro-Kin Type B 252" (Italy) device and ankle joint muscle strength was measured using an isokinetic dynamometer "Cybex Norm" (USA).

Results. Significant differences $(p<.05)$ were found between limbs for ankle plantar flexors, in non-dominant limb plantar flexors were stronger. Dynamic balance ability for dominant foot was better in comparison with nondominant foot. The correlation was found between ankle plantar flexors, evertors, invertors and between dorsal and plantar flexors for both limbs.

Conclusions. Strength improvement of muscles affects the movement of the ankle dynamic balance positively, but for the development of static and dynamic balance, proprioceptive balance training is as effective as strength training.
\end{abstract}

Keywords: lower limbs, peak torque, balance, asymmetry.

\section{INTRODUCTION}

$\mathrm{F}$

lootball is a highly coordinated sports branch in which some endurance factors using aerobic and anaerobic efforts like speed, strength, agility, balance, coordination, muscular and cardiovascular endurances commonly effect on performance (Akgün, 1996). In football, such characteristic features as frequency of tackles, sudden direction changes, jumping, leaping, ball control and technical abilities, highly depend on the level of neuromuscular coordination (proprioception). The level of neuromuscular coordination ability is in close relationship with dynamic balance (Csanadi, 1973).

In football, developing lower extremity muscles proportionally plays an important role for balanced body movements. It is believed that a special development of muscles which provide multidirectional movements of ankle will contribute to the improvement of balance ability, and this may significantly support the improvement of technical skills. Technical skills improve while using them in a balanced way in body's moving asymmetry. 
Balance and stability are important parts of many movement applications to sustain a posture (Carr \& Shepherd, 1998), they are considered to be an important aspect of sport performance (Bressel, Yonker, Kras \& Heath, 2007; Hrysomallis, McLaughlin \& Goodman, 2006) as well as ankle joint injury risk prevention (Lin, Liu, Hsieh \& Lee, 2009; McGuine, Greene, Best, \& Leverson, 2000; Troop, Ekstrand \& Gillquist, 1984). This feature can be accepted as an important factor affecting success in football. In most match situations, the lower limbs assume an important role - to provide necessary body stability during kicking, dribbles, repetitive decelerations and accelerations, rapid changing of moving direction, jumps and other manoeuvres, which are typical for football discipline (Pau et al., 2015; Teixeira, de Oliveira, Romano \& Correa, 2011). Lower extremity stabilization muscles have an important role in balancing. It can be said that strengthening these muscles affects the development of balance (Malliou, Gioftsidou, Pafis, Beneka \& Godolias, 2003).

There are different ways to evaluate muscular strength, balance and stabilizations of joints. The most useful method in sport practice to determine muscle strength and the asymmetry level between dominant/non-dominant limb and agonist/ antagonist muscles is testing with an isokinetic dynamometer (Olyaei et al., 2006). An isokinetic device makes it possible to objectively assess lower extremity muscular strength, which is extremely important for some specific movements like sprint, jumping, rapid movement direction changing, ball passing and kicking (Malliou et al., 2003).

In football the dominant foot is mostly used for activities like ball control, passing and kicking, while non-dominant limb provides balance and support functions. Greve, Alonso, Carolina and Camanho (2007), McCurdy and Langford (2006) compared foot balance index of dominant and nondominant foot in their studies and they could not find any statistically significant difference.

Malliou, Gioftsidou, Pafis, Beneka, and Godolias (2004) observed that there was a development in proprioception in a positive way and it had a blocking effect on lower extremity injury according to data derived from tool procedures which were applied on young and healthy football players and used at the end of specific balance training. In a study comparing balance parameters between two groups of footballers and not footballers, Sucan, Yilmaz, Can, and Süer (2005) determined that all the balance parameters were different for the benefit of "playing footballers" and this situation was stated as physiologic system where balance could be controlled better in playing football players. Radford (2006), however, identified that there was no difference between the parameters of professional and academicals football players.

Numerous studies have focused on the static balance testing in football players; however Pau et al. (2015) suggest that dynamic balance evaluation is more important in football because test conditions are more similar to those encountered in matches or training sessions. The main finding of the studies about the relationship between static and dynamic balance abilities in young and professional elite football players is that there are no significant correlation between those two (Hrysomallis et al., 2006; Pau et al., 2015). Static balance results do not reflect dynamic balance abilities, in football these two are not related.

Findings of Hsieh, Yang and Hsieh (2008) showed that ankle muscular strength played an important role on providing dynamic balance and they emphasized that strength training for lower extremity was important to increase dynamic balance. Mattacola and Loyd (1997) proved that strength training in plantar flexor, dorsal flexor, inversion and eversion muscle groups three times a week for 6-weeks as well as training proprioception balance improved dynamic balance. Kligyte, Ekman and Medeiros (2003) determined that weakness in lower extremity muscular strength had a negative effect on dynamic balance; however dynamic balance problems could not be resolved only increasing lower extremity muscular strength. Hamrin et al. (1982) reported that there was a weak correlation between lower extremity muscular strength and balance after disability. The aim of the research was to examine the ability to keep dynamic balance and ankle joint muscle strength in football players, and to prove the relation between the ankle joint muscle strength level and the dynamic balance ability of each foot.

\section{METHODS}

Participants. Amateur football players $(n=17$, age $22.3 \pm 5.1$ years, body mass $72.47 \pm 9.71 \mathrm{~kg}$, height $178.47 \pm 7.5 \mathrm{~cm}$, football experience $10 \pm$ 1.4 years), who regularly exercised $(12 \pm 1.3 \mathrm{~h} /$ week), played on the field in Izmir and never had any disability of ankle joint before, participated in 
the study. All participants were divided into groups of 3-5 individuals per each group for each test day.

Procedures. Before dynamic balance and muscle strength tests, participants completed "Waterloo Footedness Questionnaire - Revised" (WFQ-R) to determine their dominant and nondominant lower limb. The participants warmed up by cycling on a bike ergometer with $55-65 \mathrm{r} / \mathrm{min}$ speed for $5 \mathrm{~min}$ and after that they did static and dynamic stretching exercises for low extremity and body core muscles for about $5 \mathrm{~min}$.

Dynamic balance testing was performed using Tecnobody Pro-Kin Type B 252 Device (Italy); dominant and non-dominant limb Total Stability Index (tsi) from Equilibrium/Disequilibrium management test protocol was applied for future data proceeding. Participants were asked to stand barefoot on one leg with eyes wide opened, their arms were crossed over the chest and the knee of the contralateral limb was flexed and held at about $90^{\circ}$ without contacting the support limb. They tried to stay as still as possible for $30 \mathrm{~s}$. During the test participants were instructed to stand as motionless as possible, they were able to follow foot position and "0" point (which stated the best balance level) from a monitor in front of them. One familiarization trial per each lower limb was allowed before testing. During testing, silence was kept in the laboratory, participants joined dynamic balance test one by one. After 5 min rest football players who completed dynamic balance test (one trial per limb) went to ankle joint muscle strength testing.

During ankle joint muscle strength measurements (peak torque), one leg was placed in Cybex Norm (USA) isokinetic dynamometer in the following testing positions: knee joint flexion 80$110^{\circ}$, ankle joint testing angle fixation in eversion $20^{\circ}$, inversion $30^{\circ}$, plantar flexion $15^{\circ}$ and dorsal flexion $10^{\circ}$. Aiming at familiarization with testing exercise, participants had a trial with 3 repetitions, and then they had a $10 \mathrm{~s}$ break. The testing protocol included 5 repetitions for each limb in concentric isokinetic mode at $120^{\circ} \mathrm{s}^{-1}$ angular speed. Peak torques of ankle joint muscles (inversion, eversion, plantar and dorsal flexion muscles) were presented in foot-pounds ( $\mathrm{ft} \cdot \mathrm{lb}$ ).

All measurements were carried out in 10 days, and one hour per each participant on average was spent, $20 \mathrm{~h}$ in total.

Data analysis. Indications of 4 direction strength related to ankles in the dominant and non-dominant limbs were compared. The relationship between dominant and non-dominant limb's strength values and dynamic balance abilities was determined. SPSS statistical package (SPSS Inc., Chicago, IL, USA) for Windows 11.0 version was used for data analysis. Taking account of average values, frequency analyses, descriptive statistics, nonparametric paired groups test and correlation tests were used. Significance level $p<.05$ was accepted as statistically significant.

\section{RESULTS}

According to WFQ-R questionnaire results, 14 football players had right leg dominance and only 3 players - left leg dominance. Descriptive statistics and differences between the players' limbs, torque values of lower limb ankle joint muscles plantar/ dorsal flexors and invertors/evertors peak are presented in Table 1.

Significant differences were found between limbs for ankle plantar flexors $(p<.05)$; in nondominant limb plantar flexors were stronger. There were no statistically significant differences between dominant and non-dominant ankle dorsal flexors, invertors and evertors muscles - the average values in both limbs were rather similar.

Dominant and non-dominant limb Total Stability Index values are presented in Table 2 . Significant differences were observed between

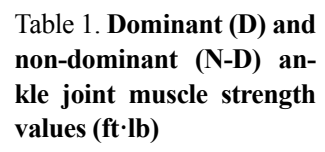

Table 1. Dominant (D) and non-dominant (N-D) ankle joint muscle strength values (ft·lb)

Note. $* p<.05$, Wilcoxon Signed Ranks Test.

\begin{tabular}{|l|c|c|c|c|c|c|c|c|}
\hline \multirow{2}{*}{ Values } & \multicolumn{2}{|c|}{ Plantar flexors } & \multicolumn{2}{c|}{ Dorsal flexors } & \multicolumn{2}{c|}{ Invertors } & \multicolumn{2}{c|}{ Evertors } \\
\cline { 2 - 9 } & D & N-D & D & N-D & D & N-D & D & N-D \\
\hline Average & 54.5 & 64.8 & 35.41 & 33.17 & 19.23 & 19.35 & 15.94 & 15.23 \\
\hline$S D$ & 23.83 & 34.87 & 12.73 & 11.39 & 5.05 & 6.54 & 4 & 3.9 \\
\hline Min & 26 & 28 & 15 & 17 & 12 & 12 & 11 & 10 \\
\hline Max & 107 & 152 & 56 & 61 & 29 & 37 & 22 & 22 \\
\hline$p$ & \multicolumn{3}{|c|}{$.02 *$} & \multicolumn{3}{|c|}{.41} & \multicolumn{3}{|c|}{.85} & \multicolumn{2}{c|}{.14} \\
\hline
\end{tabular}


average values which state dynamic balance abilities of dominant and non-dominant foot $(p<.05)$. According to the obtained data, dynamic balance for dominant foot was better in comparison with non-dominant foot.

Table 2. Total Stability Index values in the dynamic balance test

\begin{tabular}{|l|c|c|c|c|c|}
\hline \multicolumn{1}{|c|}{ Limbs } & Average & SD & Min & Max & p \\
\hline Dominant & $2.21^{\circ}$ & 0.55 & $1.27^{\circ}$ & $3.21^{\circ}$ & \\
\hline Non-dominant & $2.57^{\circ}$ & 0.8 & $1.43^{\circ}$ & $4.44^{\circ}$ & $.05^{*}$ \\
\hline
\end{tabular}

Note. ${ }^{*} p<.05$, Wilcoxon Signed Ranks Test
Relationships between average values of dominant and non-dominant limbs' dynamic balance and ankle muscle strength values can be seen in Tables 3 and 4. There were no statistically significant relationships between average values of dominant and non-dominant limbs' dynamic balance and ankle muscle strength peak torque values (inversion, eversion, plantar flexion and dorsal flexion).

The correlation was found between ankle plantar flexors, evertors and invertors as well as between dorsal and plantar flexors for both limbs.

\begin{tabular}{|l|c|c|c|c|c|}
\hline \multicolumn{1}{|c|}{ Spearman's Correlation } & $\mathbf{1}$ & $\mathbf{2}$ & $\mathbf{3}$ & $\mathbf{4}$ & $\mathbf{5}$ \\
\hline Dynamic Balance (D) & 1 & & & & \\
\hline Dominant Inversion & .33 & 1 & & & \\
\hline Dominant Eversion & .20 & $.84 * *$ & 1 & & \\
\hline Dominant Plantar Flexion & .25 & $.52^{*}$ & .38 & 1 & \\
\hline Dominant Dorsal Flexion & .21 & $.48^{*}$ & .30 & $.67^{* *}$ & 1 \\
\hline
\end{tabular}

Table 3. Correlation between dominant ankle joint muscle strength and dynamic ability average parameters

\begin{tabular}{|l|c|c|c|c|c|}
\hline \multicolumn{1}{|c|}{ Spearman's Correlation } & $\mathbf{1}$ & $\mathbf{2}$ & $\mathbf{3}$ & $\mathbf{4}$ & $\mathbf{5}$ \\
\hline Dynamic Balance (N-D) & 1 & & & & \\
\hline Non-dominant Inversion & .76 & 1 & & & \\
\hline Non-dominant Eversion & -.10 & $.63^{* *}$ & 1 & & \\
\hline Non-dominant Plantar Flexion & -.21 & $.73^{* *}$ & .30 & 1 & \\
\hline Non-dominant Dorsal Flexion & .07 & .33 & .17 & $.63^{* *}$ & 1 \\
\hline
\end{tabular}

Table 4. Correlation between nondominant ankle joint muscle strength and dynamic ability average parameters

\section{DISCUSSION}

The purpose of the present study was to examine the relationship between the dynamic balance ability and ankle joint muscle strength of the dominant and non-dominant limbs in football players. The main results of the study show lack of correlation between dynamic balance and ankle joint muscle peak torque, and significant correlation between ankle plantar flexors, evertors and invertors as well as between dorsal and plantar flexors for both limbs in amateur football players.

Numerous studies have focused on the relationship between balance and lower extremity muscles strength. In contrast with our study, Pant, Sukumar, Sharma, Pandey and Goel, (2006) stated that there was an important relationship between ankle dorsal flexion $(r=.443)$ strength and body balance. In the same study, it was found that there was a lower relationship $(\mathrm{r}=.203)$ between eversion strength and balance, while there was a weak relationship $(\mathrm{r}=.159)$ between inversion strength and balance. Cote, Brunet, Gansneder and Shultz (2005) reported that postural control and dynamic balance were needed for daily life activities and sport activities for the optimum performance. Hrysomallis (2008) observed postural balance indicators of 28 elite Australian footballers before and in the break of season, and the main finding was that footballers who had regular balance training were better in single leg balance test. According to this author, the usual football training does not improve balance ability. The results of our study showed that in footballers, dynamic balance of the dominant limb was statistically better than the one in non-dominant limbs $(p<.05)$. In contrast, Aydin, Yildiz, Yildiz, Ateşalp, and Kalyon (2002) found no significant 
difference between dominant and non-dominant lower extremity balance in gymnasts. These conclusions could reflect a sport specific training effect on balance and ankle joint muscle strength development, it could be suggested that in sport gymnastics there are more symmetric physical loads for both extremities which exclude balance and muscle strength asymmetry development. In line with a previous study (Aydin et al., 2002), Greve at al. (2007), McCurdy and Langford (2006) compared dominant, non-dominant limb balance indexes and could not find statistically significant differences between lower extremities.

Holm et al. (2004) observed a significant improvement in dynamic balance after neuromuscular preventive training program introduced to healthy female handball players and the improvement in dynamic balance was maintained one year after the start of training.

Bernier, Perrin, and Rijke (1997) observed ankle inversion and eversion torque strength and body balance and as a result, they found that ankle strength was statistically not effective on body balance. They also observed dominant and nondominant ankle inversion and eversion eccentric peak torques and they stated that non-dominant foot strength was significantly stronger than the dominant foot $(p<.05)$.

Mattacola and Loyd (1997) proved that due to ankle plantar and dorsal flexor, inversion and eversion muscle group strengthening, training three times per week for 6 weeks, dynamic balance improves. Kligyte et al. (2003) determined that weakness of lower extremity muscular strength might have an effect on dynamic balance; however dynamic balance problems could not be solved only with the increase of low extremity muscular strength.

Bozan, Koçyiğit, Cankurtaran, Gülbahar, and Peker (2010) found that in addition to strengthening exercises in postmenopausal and osteoporosis patients, balance and coordination exercises produced better results of dynamic balance functions. According to Altay (2001), the athletic skill of balance is an important factor to distinguish between good and poor athlete's performance and balance provides a positive effect on the physical development of motor skills. Troop et al. (1984) emphasized that weak balance in football players could be a risk factor for ankle disability.

It is clear that dynamic balance and lower ankle joint muscle strength play an important role in low extremity injury prevention and football players' specific motor abilities, such as agility. Agility is the ability to change the body's position efficiently, and requires the integration of balance, coordination, speed, reflexes, strength, and endurance (Brown, Ferrigno \& Santana 2000). There is no doubt that dynamic balance is an important factor for agility (Altay, 2001) and also an important component for coordinative abilities (Chelladurai, 1976; Chelladurai, Yuhasz, \& Sipura 1997; Lemmink, Elferink-Gemser, \& Visscher 2004). It is believed that dynamic balance can positively affect agility and agility training can also develop dynamic balance.

The results of the study proved that in amateur footballers dynamic balance ability of the dominant limb was statistically better than balance abilities of non-dominant limb. Besides, although it was not statistically significant, dorsal flexion strength values of the dominant foot were slightly better than dorsal flexion strength values of the non-dominant foot, and there was no statistically significant relationship between dominant and non-dominant limbs' balance and average strength values of the ankle (inversion, eversion, plantar flexion and dorsal flexion). On the other hand, it was determined that there an insignificant and negative relationship between balance ability and eversion and plantar flexion strength of non-dominant foot. Some findings of existing research support these conclusions.

As a result, we can say that strengthening muscles which play a role in the movements of the ankle may also positively affect dynamic balance. Proprioceptive balance training can also be effective on static and dynamic balance development as much as strength training. Hrysomallis (2008) observed that in a postural balance indication with only one leg of footballers before season and in the break of season, footballers who had balance training were better than those who did not. According tham, normal football training did not develop balance ability. Troop et al. (1984) emphasized that weak balance could be defined as a risk factor for disability of ankle. Results obtained in our study revealed that depending on strength and dynamic balance development with both dominant and nondominant ankle strength training, dynamic balance training can affect agility which is considered as important biomotor ability for team sports like football, and decreasing possibility of ankle disability risks. Besides some coordinative skills like balance, agility, rhythm reaction, determining 
direction in space-place, kinesthetic perception should be taken in consideration.

\section{CONCLUSION}

Strength improvement of muscles affects the movement of the ankle dynamic balance positively, but for the development of static and dynamic balance, proprioceptive balance training is as effective as strength training.

Teaching basic technical skills and developing coordination skills, forming movement symmetry is very important for sports carrier equally using dominant and non-dominant extremities.

\section{REFERENCES}

Akgün, N. (1996). Egzersiz ve Spor Fizyolojisi. Izmir: Ege Üniversitesi Basımevi, Bask1.

Altay, F. (2001). Ritmik cimnastikte iki farklı hızda yapilan chaine rotasyon sonrasinda yan denge hareketinin biyomekanik analizi. Hacettepe üniversitesi sağlık bilimleri enstitüsü doktora tezi, Ankara.

Aydin, T., Yildiz, Y., Yildiz, C., Ateşalp, S., \& Kalyon, T. A. (2002). Proprioception of the ankle: A comparison between teenaged gymnastics and controls. Foot \& Ankle International, 23(2), 123-129. doi: 10.1177/107110070202300208

Bernier, J. N., Perrin, D. H., \& Rijke, A. (1997). Effect of unilateral functional instability of the ankle on postural sway and inversion and eversion strength. Journal of Athletic Training, 32(3), 226-232.

Bozan, Ö., Koçyiğit, F., Cankurtaran, F., El, Ö., Gülbahar, S., \& Peker, Ö. (2010). Postmenopozal osteoporozda egzersiz eğitiminin kas kuvveti ve dengeye etkisi. Cilt 13, Say1 2, Sayfalar (pp. 092-098).

Bressel, E., Yonker, J. C., Kras, J., \& Heath, E. M. (2007). Comparison of static and dynamic balance in female collegiate soccer, basketball, and gymnastics athletes. Journal of Athletic Training, 42(1), 42-46. PMCID: PMC1896078

Brown, L. E., Ferrigno, V. A., \& Santana, J. C. (2000). Training for speed, agility and quickness. Champaign, IL: Human Kinetics.

Carr, J. H., \& Shepherd, R. (1998). Neurological rehabilitation: Optimising motor performance. Oxford: Butterworth-Heineman.

Chelladurai, P. (1976). Manifestations of agility. Journal of the Canadian Association of Health, Physical Education and Recreation, 42(3), 36-41.

Chelladurai, P., Yuhasz, M. S., \& Sipura, R. (1977). Reactive agility test. Perceptual and Motor Skills, 44, 1319-1324.

Cote, K. P., Brunet, M. E., Gansneder, B. M., \& Shultz, S. J. (2005). Effects of pronated and supinated foot postures on static and dynamic postural stability. Journal of Athletic Training, 40(1), 41-46. PMID: 15902323

Csanadi, A. (1973). Futbol teknik-taktik türkiye futbol federasyonu teknik kitap yayınları. Ankara.

Greve, J., Alonso, A., Carolina, P. G., \& Camanho, G. L. (2007). Correlation between body mass index and postural balance. São Paulo, Brazil, Clinics, 62(6), 717-720.
Hamrin, E., Eklund, G., Hillgren, A. K., Borges, O., Hall, J., \& Hellstrom, O. (1982). Muscle strength and balance in post-stroke patients. Journal of Medical Sciences, 87, 11-26.

Holm, I., Fosdahl, M. A., Friis, A., Risberg, M. A., Myklebust, G., \& Sten, H. (2004). Effect of neuromuscular training on propriocepsition, balance, muscle strength, and lower limb function in female team handball players. Clinical Journal of Sport Medicine, 14, 88-94. PMID: 15014342

Hrysomallis, C., McLaughlin, P., \& Goodman, C. (2006). Relationship between static and dynamic balance tests among elite Australian footballers. Journal of Science and Medicine in Sport, 9, 288-291. doi: http://dx.doi. org/10.1016/j.jsams.2006.05.021

Hrysomallis, C. (2008). Preseason and midseason balance ability of Professional Australian footballers. Journal of Strength and Conditioning Research, 22(1), 210-211.

Hsieh, C. J., Yang, S. W., \& Hsieh, L. F. (2008). Role of muscle strength in dynamic balance for subjects with knee osteoarthritis, In: 4th Kuala Lumpur International Conference on Biomedical Engineering, Vol. 10 (pp. 798-801).

Kligytė, I., Ekman, L. L., \& Medeiros, J. M. (2003). Relationship between lower extremity muscle strength and dynamic balance in people post-stroke. Medicina, 39(2), 122-128.

Lemmink, K. A. P. M., Elferink-Gemser, M. T., \& Visscher, C. (2004). Evaluation of the reliability of two field hockey specific sprint and dribble tests in young field hockey players. British Journal of Sports Medicine, $38,138-142$.

Lin, W. H., Liu, Y. F., Hsieh, C. C. C., \& Lee, A. J. Y. (2009). Ankle eversion to inversion strength ratio and static balance control in the dominant and non-dominant limb of young adults. Journal of Science and Medicine in Sport, 12, 42-49.

Malliou, P., Gioftsidou, A., Pafis, G., Beneka, A., \& Godolias, G. (2004). Proprioseptive training (balance exercises) reduces lower extremity injuries in young soccer players. Journal of Back and Musculoskeletal Rehabilitation, 17, 101-104.

Malliou, P., Ispirlidis, I., Beneka, A., Taxildaris, K., \& Godolias, G. (2003). Vertical jump and knee extensors isokinetic performance in professional soccer players 
related to the phase of the training period. Isokinetics and Exercise Science, 11, 165-169.

Mattacola, C. G., \& Loyd, J. W. (1997). Effects of a 6-week strength and proprioception training program on measures of dynamic balance: A single-case design. Journal of Athletic Training, 32(2), 127-135.

McCurdy, K., \& Langford, G. (2006). The relationship between maximum unilateral squat strength and balance in young adult men and women, Journal of Sports Science and Medicine, 5, 282-288. PMID: PMC3827570

McGuine, T. A., Greene, J. J., Best, T., \& Leverson, G. (2000). Balance predictor of ankle injuries in high school basketball players. Clinical Journal of Sport Medicine, 10, 239-244. PMID: 11086748

Olyaei, G. R., Hadion, M. R., Talebian, S., Bagheri, H., Malmir, K., \& Olyaei, M. (2006) "the effect of muscle fatigue on knee flexor to extensor torque ratios and knee dynamic stability". The Arabian Journal of Science and Engineering, 31(2c), 212-127.

Pant, H., Sukumar, K., Sharma, H., Pandey, A. K., \& Goel, S. N. (2006). Correlation between muscles strength in relation to dorsi flextion, planter flextion, eversion \& inversion strength with body balance, India Mo-Tu. New Trends in Movement Analysis, S557, 61-62.

Pau, M., Arippa, F., Leban, B., Corona, F., Ibba, G., Todde, F., \& Scorcu, M. (2015). Relationship between static and dynamic abilities in Italian professional and youth league soccer players. Physical Therapy in Sport, 16(3), 236-241. doi: 10.1016/j.ptsp.2014.10.003.

Radford, D. (2006). Study of balance in elite and academy football players. Retrieved form http://www. mds.qmw.ac.uk/sportsmed/research.

Sucan, S., Yilmaz, A., Can, Y., \& Süer, C. (2005). Aktif futbol oyuncularının çeşitli denge parametrelerinin değerlendirilmesi, erciyes üniversitesi sağlı bilimleri dergisi, Journal of Health Sciences, 14(1), 36-42.

Teixeira, L. A., de Oliveira, D. L., Romano, R. G., \& Correa, S. C. (2011). Leg preference and interlateral asymmetry of balance stability in soccer players. Research Quarterly for Exercise \& Sport, 82(1), 21-27. doi: 10.1080/02701367.2011.10599718

Troop, H., Ekstrand, J., \& Gillquist, J. (1984). Stabiliometry in functional instability of the ankle and its value in predicting injury. Medicine and Science in Sports and Exercise, 16, 64-66. 